\title{
PHYSIOLOGICAL RESPONSE OF ZARAIBI BILLY GOATS SPERMATOZOA TO SOYBEAN LECITHIN ADDITION AS AN ALTERNATIVE TO EGG YOLK VARIETIES IN SEMEN EXTENDERS
}

\section{E.I. Khalifa}

Animal Production Research Institute (APRI), Department of Sheep and Goat Research, Ministry of Agriculture, Dokki, Giza, Egypt

Corresponding author: xyezz@yahoo.com

\section{SUMMARY}

The present study was designed to determine the influence of cryopreservation action of extenders containing plant (soybean lecithin, SBL) or animal (domestic birds' egg yolk) origins on freezability and fertility of billy goat spermatozoa. Thus, semen ejaculates (thirty-six ejaculates) were collected, evaluated and extended in Tris-citric acid with either SBL or egg yolk (EY) derived from hen (HEY), duck (DEY), goose (GEY), quail $(Q E Y)$, turkey (TEY) and pigeon (PEY). The diluted semen was packaged in $0.5 \mathrm{ml}$ French straws, equilibrated for 3 hours at $5^{\circ} \mathrm{C}$ then frozen in liquid nitrogen $\left(\right.$ at $-196^{\circ} \mathrm{C}$ ). The thawing of straws was attained at $37^{\circ} \mathrm{C}$ for 60 sec. Percentages of progressive sperm motility, viability of sperms and injury of acrosome were evaluated at post - dilution (PD), post - equilibrium (PE) and post - thawing (PT). Fertility rate was carried out with 24 nanny goats divided into two groups $(N=12 /$ group) and inseminated with the best cryosurvival extenders. The results revealed a non-significant difference between plant and bird origin extenders during PD and PE stages. In contrast, the PT was higher $(P<0.05)$ in motility and viability with $S B L$ and DEY extenders than other EY species however, the same trend did not occur between SBL and DEY extenders. The values of acrosomal abnormality was lower $(P<0.05)$ in $S B L$ and DEY extenders than other EY extenders. The nanny goats inseminated by $S B L$ and DEY extenders had a conception rate of $58.33 \%$ and $50.00 \%$, respectively.

These results indicate that the spermatozoa that were preserved in either SBL or DEY extenders could protect the sperm cells during $P D, P E, P T$ and results in the best fertility rate. Furthermore, the present study demonstrates that SBL may represent a suitable alternative to egg yolk for semen cryopreservation in livestock species.

\section{Keywords: Billy goats' semen, plant and animal cryopreservation origins, fertility rate}

\section{INTRODUCTION}

Egg yolk (EY) of different domestic birds has been shown to have a beneficial effect on sperm cryopreservation as a protector for the sperm plasma membrane and acrosome against temperature-related injury. The EY Phospholipids, polyunsaturated fatty acids (PUFAs) and cholesterol could prevent cold shock, osmotic stress, ice crystal formation or oxidative damage and loss of sperm fertility ( $\mathrm{Hu}$ et $a l ., 2010)$. On the contrary, the EY is representing a potential risk of contamination of artificial insemination (AI) by bacteria and mycoplasma (Rosato \& Iaffaldano, 2013). Actually, EY has some problems. Van Reenen and Griffin (1994) reported that the deleterious effects of the aromatic amino acid oxidation (AAAO) is further exacerbated by components of egg yolk which is used as a cryoprotectant for the freezing of mammalian semen. During sperm metabolism, AAAO enzyme becomes active following the death of sperm and increasing hydrogen peroxide $\left(\mathrm{H}_{2} \mathrm{O}_{2}\right)$, a metabolic product of the enzyme, is known to be toxic to the remaining live sperm (Saraswat et al., 2014). Furthermore, EY contains micro elements that result in an increase of extender's viscosity, inhibition of sperm respiration and diminish sperm motility. For the same phenomenon, Salmani et al. (2013) stated that the dilution of goat semen using a diluents containing egg yolk can have a detrimental effect on the quality of the sperm cells during extension, freezing and thawing due to the presence of egg yolk - coagulating enzyme (EYCE) and bulbourethral gland secretion glycoprotein (BUSgp60). In this context, reports suggested that EY from avian species have different combinations of PUFAs, phospholipids and cholesterol, which resulted in different cryopreservation effects on the sperm membrane (Kulaksiz, et al., 2010). On the other hand, egg yolk (EY) could attain the greatest spermatozoa protection, but in recent years there was an increasing demands for alternative egg yolk in extenders due to variability composition, risk of microbial contamination and presence of steroid hormones. Hence, the alternative to EY- based extender might be soybean lecithin-based (SBL) extender (Najafi et al., 2014). The extender contains soybean lecithin (SBL) as an egg yolk substitute has become available for the cryoprotection of the animal spermatozoa. This evidence suggests that SBL contains a major phospholipid that plays an important role in building sperm cell membrane and supplies sperm freezability (Emamverdi et al. (2013). Finding of Khalifa and Abdel-Hafez (2014) using extenders containing

Issued by The Egyptian Society of Animal Production 
soybean lecithin at $3.5 \%$ cryopreserved the ram sperm and exceeded the conventional hen egg yolkbased in fertility. Therefore, the following experiment was intended to study the effect of either soybean lecithin or egg yolk from different avian domestic species on sperm characteristics of Zaraibi billy goat. In addition, fertility rate was carried out with the best cryoprotective extenders.

\section{MATERIALS AND METHODS}

This experiment was carried out at El-Serw Experimental Farm, Damietta governorate belonging to Animal Production Research Institute (APRI), Ministry of Agriculture, Egypt. The duration of the trial was between June and November (2013).

\section{Semen collection}

Thirty - six semen ejaculates were collected from three adult billy goats (as two ejaculates / week / up to six weeks) using an artificial vagina method. Each ejaculate was observed visually, semen samples that were having a motility $>75 \%$, viability $>85 \%$ and integrity acrosome $>85 \%$ were utilized in the extension protocol.

\section{Preparation of diluents and freeze - thawing process}

The soybean lecithin (SBL) was supplemented at $2.5 \%$ using Tris - citric glucose (TCG) buffer. However, $2.5 \% \mathrm{ml}$ egg yolk (EY) of avian specie birds such as hen, duck, goose, quail, turkey and pigeon was supplemented in TCG buffer to perform HEY, DEY, GEY, QEY, TEY and PEY diluents applying the same rate, respectively. The extension rate designed to be used is one - step method at room temperature. The extender was regulated by Evans and Maxwell (1987) and either plant or birds origin extenders as demonstrated in Table 1.

Table 1. The composition of extenders with either plant or bird origins for Zaraibi billy goats semen

\begin{tabular}{lccccccc}
\hline Ingredients & \multirow{2}{*}{ *SBL } & \multicolumn{7}{c}{ Egg yolk of avian species } \\
\cline { 3 - 8 } & & HEY & DEY & GEY & QEY & TEY & PEY \\
\hline Tris (g) & 3.786 & 3.786 & 3.786 & 3.786 & 3.786 & 3.786 & 3.786 \\
Glucose (g) & 0.625 & 0.625 & 0.625 & 0.625 & 0.625 & 0.625 & 0.625 \\
Citric acid (g) & 2.172 & 2.172 & 2.172 & 2.172 & 2.172 & 2.172 & 2.172 \\
Soybean lecithin,\% & 2.500 & - & - & - & - & - & - \\
Hen egg yolk, \% & - & 2.500 & - & - & - & - & - \\
Duck egg yolk, \% & - & - & 2.500 & - & - & - & - \\
Goose egg yolk, \% & - & - & - & 2.500 & - & - & - \\
Quail egg yolk, \% & - & - & - & - & 2.500 & - & - \\
Turkey egg yolk, \% & - & - & - & - & - & 2.500 & - \\
Pigeon egg yolk, \% & - & - & - & - & - & - & 2.500 \\
Glycerol (v/v) & 5.000 & 5.000 & 5.000 & 5.000 & 5.000 & 5.000 & 5.000 \\
Penicillin (IU/ml) & 100.000 & 100.000 & 100.000 & 100.000 & 100.000 & 100.000 & 100.000 \\
Streptomycin (mg /ml) & 100.000 & 100.000 & 100.000 & 100.000 & 100.000 & 100.000 & 100.000 \\
Distilled water to & $100 \mathrm{ml}$ & $100 \mathrm{ml}$ & $100 \mathrm{ml}$ & $100 \mathrm{ml}$ & $100 \mathrm{ml}$ & $100 \mathrm{ml}$ & $100 \mathrm{ml}$ \\
\hline SBL: & & & & & & & \\
\hline
\end{tabular}

SBL: soybean lecithin, HEY: hen egg yolk, DEY: duck egg yolk, GEY: goose egg yolk, QEY: quail egg yolk, TEY: turkey egg yolk and PEY: pigeon egg yolk.

*SBL: Sigma Chemical Co. (St. Louis, MO, USA).

After dilution, the sperm was drawn into $0.50 \mathrm{ml}$ French straws and sealed with polyvinyl chloride powder; each straw was adjusted to contain 350 $400 \times 10^{6}$ motile sperm. Straws were equilibrated at $5^{\circ} \mathrm{C}$ for 3 hours and after equilibration period; the refrigerated straws were suspended on metal rack in foam box $(35 \times 17 \times 20 \mathrm{~cm})$ above the surface of the liquid nitrogen vapor for 15 minutes by $5 \mathrm{~cm}$. Then, frozen straws were plunged into the liquid nitrogen at $-196^{\circ} \mathrm{C}$ for $8 \mathrm{~min}$. Subsequently, frozen straws were collected in foam box and stored in liquid nitrogen container until thawing steps. After storage for a period of 24 hours, the semen straws were thawed in a water bath at $37^{\circ} \mathrm{C}$ for $60 \mathrm{sec}$.

\section{Semen Evaluation}

In different stages of cryopreservation technique such as post - dilution (PD), post - equilibration (PE) and post - thawing (PT), the percentages of sperm motility, viability of spermatozoa and acrosomal abnormality were implemented according to Khalifa and Abdel - Hafez (2013).

\section{Fertility test}

The fertility performance was managed using twenty - four Zaraibi nanny goats satisfactorily homogeneous in live body weight, age and body conditions. The nanny goats were divided into two groups $(\mathrm{N}=12 /$ group) and inseminated by frozen thawed sperm cryopreserved in either SBL or DEY extenders. The insemination semen straws of either SBL or DEY were collected and extended from the same billy goat to avoid the semen characteristics variance. The insemination protocol started after 12 hours of nanny goat displayed oestrous cycle using two frozen - thawed straws within 12 hours as an interval period between received $1^{\text {st }}$ and $2^{\text {nd }}$ frozen thawed straws as described by (Khalifa and Abdel - 
Hafez, 2014). The pregnancy rate was attained after doe passed an oestrous cycle without returning to heat. The fertility performance was calculated as the pregnancy rate (number of does conceived/ number of does inseminated), percentage of does kidded (number of does kidded / number of does conceived), twins rate (number of does kidded twins / total number of does kidded), triplet rate (number of does kidded triplet / total number of does kidded). Sexing kids $\%$ (male: female $)=$ number of born kids in each sex/Total number of born kids and litter size $=$ number of total born kids / number of does kidded.

\section{Statistical analysis}

The statistical analysis was performed using oneway analysis of variance of IBM SPSS (2013) version 22.0. The data were represented as mean \pm $\mathrm{SE}$ and a $\mathrm{P}$ value of $<0.05$ considered as statistically significant using Duncan multiple range test of the same program of SPSS.

The following model was used for analysis of variance:

$\mathrm{Y}_{\text {mdqtk }}=\mu+\mathrm{E}_{\mathrm{m}}+\mathrm{S}_{\mathrm{d}}+\mathrm{S}_{\mathrm{q}}+\mathrm{S}_{\mathrm{t}}+\mathrm{e}_{\mathrm{mdqtk}}$

$\mathrm{Y}_{\text {mdqtk }}=$ observation, $\mu=$ overall mean, $\mathrm{E}_{\mathrm{m}}=$ extender media $(\mathrm{m}=7), \mathrm{S}_{\mathrm{d}}=$ sperm parameters post - dilution $(\mathrm{d}=36), \mathrm{S}_{\mathrm{q}}=$ sperm parameters post - equilibration $(\mathrm{q}=36), \mathrm{S}_{\mathrm{t}}=$ sperm parameters post - thawing $(\mathrm{t}=36)$, $\mathrm{e}_{\mathrm{mdqtk}}=$ experimental errors.

\section{RESULTS AND DISCUSSION}

The sperm motility, viability and acrosomal abnormality at the steps of cryopreservation are shown in (Figures 1, 2 and 3, respectively). The results indicate that there were differences $(\mathrm{P}>0.05)$ between SBL, HEY, DEY, GEY, QEY, TEY and PEY extenders on the measured physiological sperm parameters during PD and PE. Actually, using extenders contain either DEY or SBL resulted in higher $(\mathrm{P}<0.05)$ physiological sperm characteristics (motility, viability and acrosomal abnormality) than HEY, GEY, QEY, TEY and PEY extenders. Intriguingly, the recovery rate of the total frozenthawed motility, viable sperm and integrity acrosome were higher $(\mathrm{P}<0.05)$ using SBL than avian species egg yolks extender. Theoretically, the degree of sperm viability deterioration depends on several factors, e.g., the nature and concentration of cryoprotectants and component of the diluents used for freezing and thawing (Emamverdi et al., 2013). The current study corroborative SBL extender could be attained post-thaw progressive sperm motility $(53.93 \%)$, post-thaw viability sperm $(69.58 \%)$ and the lowest post-thaw acrosomal abnormality (37.08\%). Similar results were found by de-Paz et al. (2010) who stated that soybean lecithin is an efficient ingredient for the protection of the animal spermatozoa from cold shock and freezing process. Furthermore, these authors stated that semen extender with soybean lecithin at 3.5\% showed a higher concentration of phospholipids which optimized to preserve the individual sperm motility, viability and intact acrosomes. In addition, Yotov (2015) concluded that extenders containing soybean lecithin at $1.5 \%(\mathrm{w} / \mathrm{v})$ provided the best motility and viability of the chilled-stored goats' spermatozoa. In recent decades, soybean lecithin was demonstrated to be safer than egg yolk in terms of biosecurity and it is used for sperm cryopreservation in ram (Najafi et al., 2014), goats (Chelucci et al., 2015). It is known that extender contained soybean lecithin could change mitochondrial inner membrane function by increasing outer membrane permeability which releases soluble intermembrane proteins to activate metabolic pathways. Similar trend was observed by Del valle et al. (2012) who established that lecithin protect sperm cells; activate mitochondrial functionality and lengthy sperm motility. The lecithin was reported to have neither cytotoxic effect nor negative effect on sperm motility, whereas lysophosphatidylcholine and other fatty acids in egg yolk have inhibitory effects on sperm motility and induce acrosomal damage (Alvarez - Rodríguez et al., 2013). Likewise, Marisa Bezjian et al. (2013) indicated that sperm in soy - based Bioxcell ${ }^{\circledR}$ displayed more viability and intact acrosomes than sperm in Tris - egg yolk. The present results clearly demonstrate that DEY extender has the best cryoprotective action after frozen - thawed in motility, viability and the lowest acrosomal abnormality; it achieved 52.78, 68.42 and $37.67 \%$ compared to the other avian egg yolk, respectively. In the present study, the percentages of thawing sperm characteristics in DEY extender provided excellent cryoprotective action for sperm compared to other egg yolk birds. These findings are supported by Kulaksiz et al. (2010) who recommended that the basic components of duck egg yolk had more ratios of fatty acids, phospholipids classes, monounsaturated fatty acid and phosphotidylionsitol than egg yolk obtained from avian specie birds. Finding of, Gholami et al. (2012) demonstrated that duck egg yolk might be superior to chicken egg yolk for cryopreservation of ram spermatozoa in Triscitric yolk extender. On the other hand, Waheed et al. (2012) stated an improvement of sperm parameters when the buffalo semen frozen in extenders containing duck egg yolk. Thus, the improvement or decline in post - thawing quality of mammalian spermatozoa with egg yolk of different avian species in the freezing extender may be attributed to the differences in the biochemical composition of yolk (El-Sharawy et al., 2012). The preserving action of birds' egg yolk depends on cholesterol and lecithin that prevented the ice crystal formation, protected sperm plasma membranes during cold shock and freeze-thawing process. This finding was coincided with $\mathrm{Hu}$ et al. (2010) who assured that cholesterol modulates fluidity of sperm membranes by interacting with the fatty acyl chains of the phospholipids, maintains phospholipids in a random and lamellar arrangement as temperature decreases. Duck egg yolk cholesterol could reduce the 
sensitivity of sperm membranes to cooling damage by eliminating or at least minimizing the lateral phase separation of the lipids. Subsequently, this observation is harmonious with Szafner et al. (2012) who suggested that cholesterol concentration $(\mathrm{mg} / \mathrm{g}$ yolk) in yolks among different avian species such as chicken, ducks, turkey, quail and goose were 15.4, $18.8,16.7,7.78$ and 17.2, respectively. Furthermore, $\mathrm{Wu}$ et al. (2012) indicated that average lecithin concentration in hen and duck egg yolk was 2.94 and $3.81 \%$, respectively. On the other hand, it is well documented that duck egg yolk consists $0.52 \%$ of Docosahexaenoic acid (DHA) which higher than chicken $(0.28 \%)$ and quail $(0.39 \%)$ which appeared to have an important role to active ingredient for the cryoprotection morphological spermatozoa (Nasiri et al. 2012). The DHA has critical role in maintaining fluidity of sperm plasma membrane during cryopreservation which in turn prevents lipid peroxidation that causes sperm plasma membrane damage. Similarly, Kaeoket and Chanapiwat (2013) observed that DHA in duck egg yolk has a similar manner of lactose - egg - yolk (LEY) in based freezing extender that improves the quality of frozen semen thus; DHA of duck egg yolk could achieve improvement in frozen-thawed semen qualities instead of chicken egg yolk.

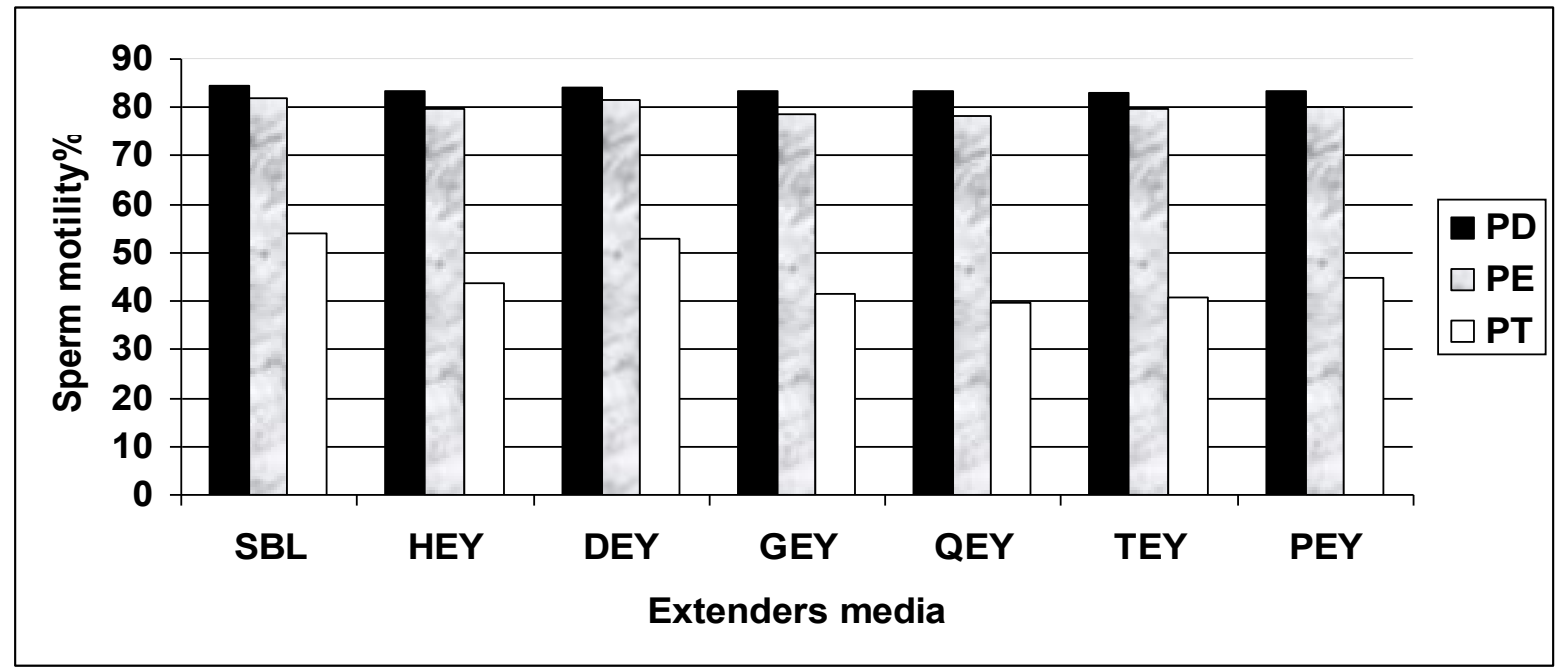

Fig. 1. Sperm motility in billy goats semen during cryopreservation stages using soybean lecithin and different avian species of egg yolk.

SBL: soybean lecithin, HEY: hen egg yolk, DEY: duck egg yolk, GEY: goose egg yolk, QEY: quail egg yolk, TEY: turkey egg yolk and PEY: pigeon egg yolk.

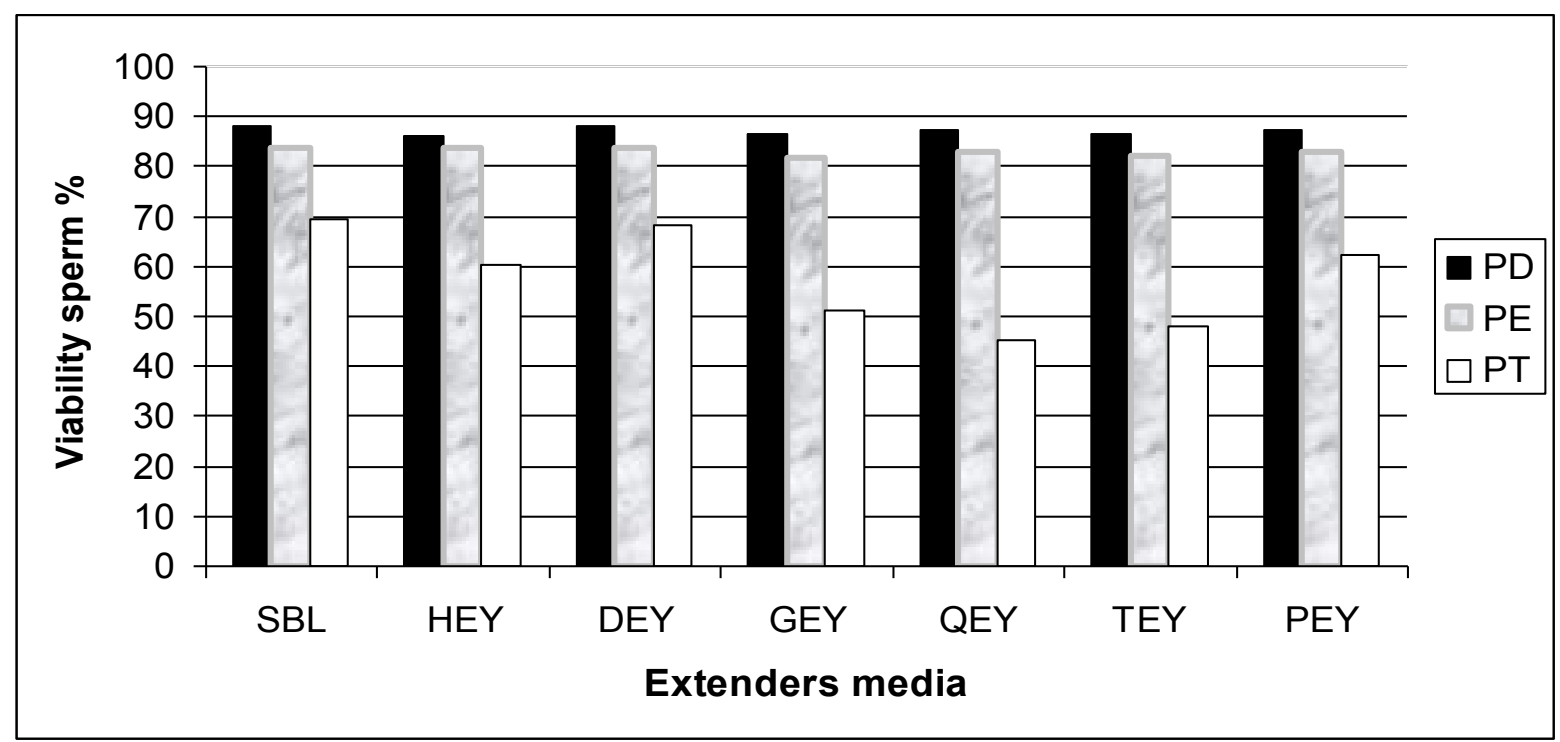

Fig. 2.Viability sperm in billy goats semen during cryopreservation stages using soybean lecithin and different avian species of egg yolk.

SBL: soybean lecithin, HEY: hen egg yolk, DEY: duck egg yolk, GEY: goose egg yolk, QEY: quail egg yolk, TEY: turkey egg yolk and PEY: pigeon egg yolk. 


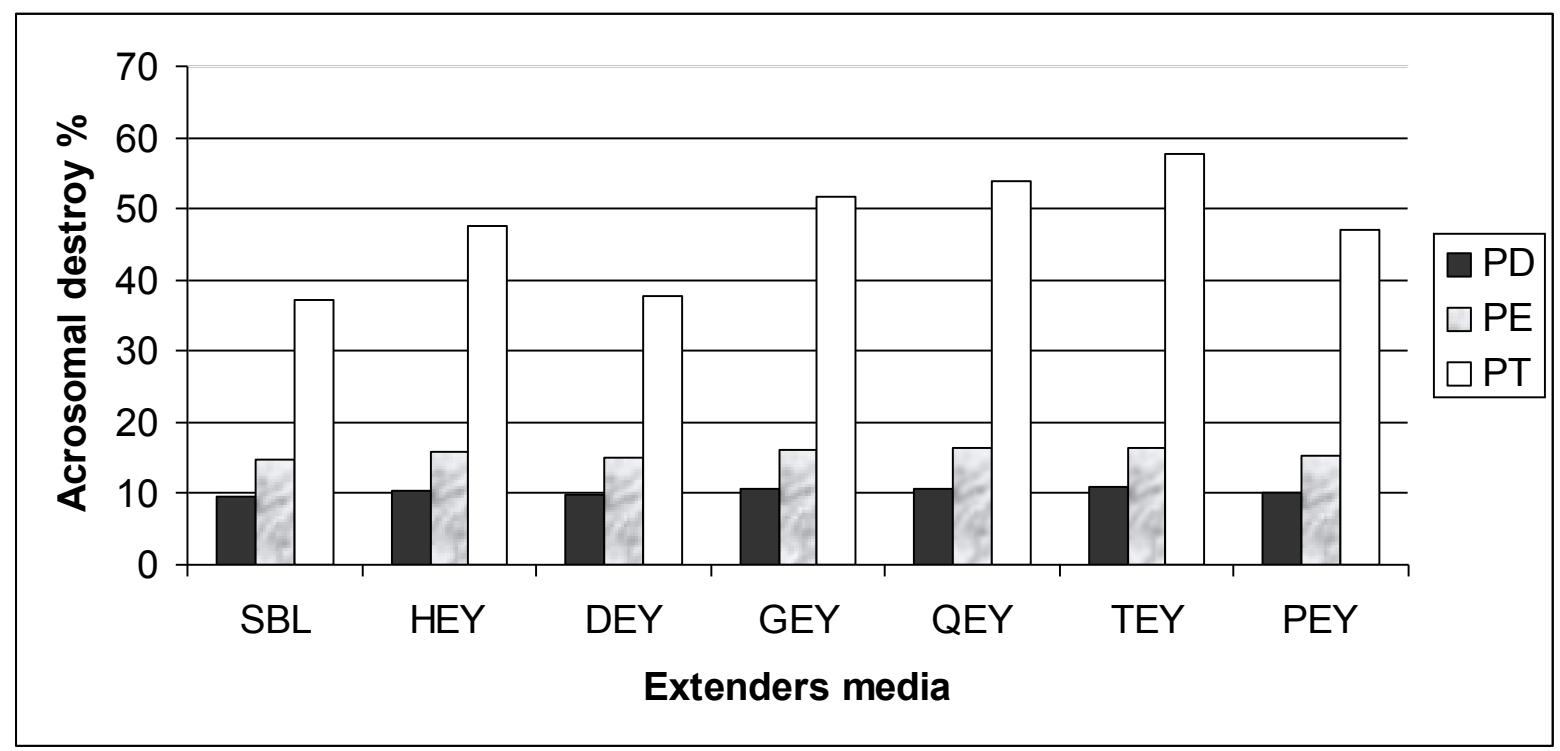

Fig. 3. Acrosomal destroy in billy goats semen during cryopreservation stages using soybean lecithin and different avian species of egg yolk

SBL: soybean lecithin, HEY: hen egg yolk, DEY: duck egg yolk, GEY: goose egg yolk, QEY: quail egg yolk, TEY: turkey egg yolk and PEY: pigeon egg yolk.

\section{Fertility rate}

Results in Table (2) show the influence of either SBL or DEY as semen extenders on the fertility rate parameters. The pregnancy rate was higher for spermatozoa extended by SBL (58.33\%) dilute than that in DEY $(50.00 \%)$ dilute. This discrepancy of pregnancy rate with DEY extender may be due to an increase of aromatic amino acid oxidase (AAAO) enzyme that is released from dead spermatozoa which increased reactive oxygen species (ROS) and reduced PUFAs in extender. Similar conclusions have come from Agarwal et al. (2005) who found that PUFAs in egg yolk decreased dramatically when the dead spermatozoa released AAAO enzyme and ROS attacked survival spermatozoa which reflected on decreasing progressive motility, increasing mid piece abnormalities and inhibited sperm oocyte fusion. On the other hand, bacterial contamination which is present in egg yolk can release endotoxins that reduce the fertilization capacity of sperm and ATP synthesis. Similar results have been obtained by Sukho et al. (2013) who defined that growth of microbes egg yolk inhibition glycolysis cycle which forces the sperm mitochondria to work at a higher level to generate energy lead to diminish pyruvic acid in seminal plasma appeared to be a marked short term of viable sperm too long. In the present study, the best fertility rate was obtained with SBL spermatozoa compared to those spermatozoa in the DEY extender. This is in accordance with a previous study by Emamverdi et al. (2013) who reported that SBL has a low density lipoprotein, conserve phospholipids membrane during cryopreservation which is reflected on sperm motility and fertility. Independently of extender used SBL increased viscosity of the extender, which has been complicated motility and cell membrane integrity (Najafi et al., 2014). The highest pregnancy rate occurred with SBL was related to possibly displacement cardiolipin (kind of diphosphatidylglycerol lipid activated mitochondria enzymes) to mitochondrial membrane that reflected a high motility value after thawing (Peña et al., 2009). Likewise, the mitochondria may play a tender role in the energy maintenance for sperm motility one of the major parameters related to fertility. These observations were explained with Shahani et al. (2012) who suggested that lecithin provides better protection of mitochondria than animal originated, by playing a protective role for mitochondria during cryopreservation due to its low viscosity and improves the kinematics of mitochondria. According to this information, Del valle et al. (2012) reported that effectiveness of soybean lecithin to protect spermatozoa against cryoinjury is because it increased proportions of viable spermatozoa post thawed that reflected on sperm motility and fertility. Otherwise, Chelucci et al. (2015) demonstrated that lecithin can be considered as a suitable alternative to egg yolk in semen cryopreservation, because it ensures higher fertilization rates and a better protection from membrane damage by cold shock. Also, the last authors showed that lecithin and egg yolk extenders obtained 66.2 and $38.7 \%$ in vitro fertilization test, respectively. On the other hand, Khalifa and Abdel - Hafez, (2014) concluded that SBL diluent could ameliorate the quality of sperm cryopreservation and heighten fertility rate of ram spermatozoa $(63.64 \%)$ compared to extender contained hen egg yolk (54.55\%). 
Table 2. The fertility rate of Zaraibi billy goats frozen using either SBL or DEY extenders

\begin{tabular}{lcc}
\hline Item & \multicolumn{2}{c}{ Semen extenders } \\
\cline { 2 - 3 } & & DEY \\
\hline Number of does inseminated & 12.00 & 12.00 \\
Number of does conceived & 7.00 & 6.00 \\
Pregnant rate, \% & 58.33 & 50.00 \\
Number of does kidded & 7.00 & 6.00 \\
Does Kidded, \% & 100 & 100 \\
Total number of kids at birth & 20.00 & 15.00 \\
Number of does kidded twins & 1.00 & 3.00 \\
Twins rate, \% & 14.29 & 50.00 \\
Number of does kidded triplet & 6.00 & 3.00 \\
Triplet rate, \% & 85.71 & 50.00 \\
Number of female kids & 10.00 & 6.00 \\
Female rate, \% & 50.00 & 40.00 \\
Number of male kids & 10.00 & 9.00 \\
Male rate, \% & 50.00 & 60.00 \\
Litter size & 2.88 & 2.50 \\
\hline
\end{tabular}

\section{CONCLUSION}

Based on the results of this study, semen extenders containing either a source of plant origin as soybean lecithin or bird origin as duck egg yolk remarkably cryoprotected Zaraibi billy goat spermatozoa examined post-diluent, post equilibration and post - thawing compared to other different egg yolk of other birds. Additionally, SBL extender as cryosurvival materials is considered a new strategy to protect spermatozoa and also improve sperm fertility compared to DEY extender.

\section{REFERENCES}

Agarwal, A., S. A. Prabakaran and T. M. Said, 2005. Prevention of oxidative stress injury to sperm. Journal Andrology, 26: 654 - 660.

Alvarez - Rodríguez, M., M. Alvarez, L. Anel López, C. Martínez - Rodríguez, F. Martínez Pastor, S. Borragan, L. Anel and P. de Paz, 2013. The antioxidant effects of soybean lecithin - or low-density lipoprotein - based extenders for the cryopreservation of brown - bear (Ursus arctos) spermatozoa. Reproduction Fertility and Development, 25 (8): 1185 - 1193.

Chelucci, S., V. Pasciu, S. Succu, D. Addis, G. G. Leoni, M. E. Manca, S. Naitana and F. Berlinguer, 2015. Soybean lecithin - based extender preserves spermatozoa membrane integrity and fertilizing potential during goat semen cryopreservation. Theriogenology, 83 (6): 1064 - 1074

Del valle, I. A. Gomez - duran, W. V. Holt, T. Muino - blanco and J. A. Cebrian - perez, 2012. Soy lecithin interferes with mitochondrial function in frozen - thawed ram spermatozoa. Journal of Andrology, 33 (4): 717 - 725.

de-Paz, P., M. C. Esteso, M. Alvarez, M. Mata, C. A. Chamoro and L. Anel, 2010. Development of extender based on soybean lecithin for its application in liquid ram semen. Theriogenology, 74 (2010): 663 - 671.

El - Sharawy, M. E., I. S. El - Shamaa, M. A. R. Ibrahim, I. M. Abd El - Razek and E. M. El Seify, 2012. Effect of low density lipoproteins in extender on freezability and fertility of Egyptian buffalo bull semen. Animal Science, Series D, LV: 114 - 120.

Emamverdi, M., M. Zhandi, A. Zare Shahneh, M. Sharafi and A. Akbari - Sharif, 2013. Optimization of ram semen cryopreservation using a chemically defined soybean lecithin based extender. Reproduction Domestic Animal, 48(6): 899 - 904.

Evans, G. and W. M. C. Maxwall, 1987. Frozen Storage of Semen. In: Salamon's Artificial Insemination of Sheep and Goats. Edit by butterworths, Sydney, pp: 122 - 141.

Gholami, M., Z. Faraji and M. J. Zamiri, 2012. Effect of egg yolk of four avian species on the cryopreserved ram spermatozoa. Iranian Journal of Veterinary Research, Shiraz University, 13 (No. 1, Ser. No. 38): 23 - 27.

Jian - Hong, H., Q. W. Li, L. S. Zan, Z. L. Jiang, J. H. An, L. Q. Wang and Y. H. Jia, 2010. The cryoprotective effect of low - density lipoproteins in extenders on bull spermatozoa following freezing - thawing. Animal Reproduction Science, 117: $11-17$.

Kaeoket, K. and P. Chanapiwat, 2013. DHA analysis in different types of egg yolks: its possibility of 
being a DHA source for boar semen cryopreservation. Thailand Journal Veterinary Medicine, 43 (1): 119 - 123.

Khalifa, E. I. and M. A. M. Abdel - Hafez, 2013. Evaluation of different levels of soybean lecithin as an alternative to egg yolk for cryopreservation of goat and ram spermatozoa. Journal of Animal and Poultry Sciences, Suez Canal University, 13 (1): $1-6$.

Khalifa, E. I. and M. A. M. Abdel - Hafez, 2014. Effect of soybean lecithin-based semen extender on freezability and fertility of Rahmani ram spermatozoa. Egyptian Journal of Sheep and Goat Sciences, 9 (1): 59 - 66.

Kulaksiz, R., C. Cebi, E. Akcay and A. Daskin, 2010. The protective effect of egg yolk from different avian species during the cryopreservation of Karayaka ram semen. Small Ruminant Research, 88: 12 - 15.

Marisa Bezjian, D. V. M., A. C. Z. M. Noha Abou Madi, D. G. V. Kollias, A. C. Z. M. Dipl, E. P. John, D. V. M. Soon Hon Cheong, A. C. T. Dipl, A. Katherine and D. V. M. Beltaire, 2013. Characterization and cryopreservation of semen from endangered Markhor goats (capra falconeri heptneri) with evaluation of reproductive seasonality. Journal of Zoo and Wildlife Medicine, 44 (3): 672 - 685.

Najafi, A., M. H. Najafi, Z. Zanganeh, M. Sharafi, F. Martinez - Pastor and H. Adeldust, 2014. Cryopreservation of Ram Semen in Extenders Containing Soybean Lecithin as Cryoprotectant and Hyaluronic Acid as Antioxidant. Reproduction in Domestic Animals, 49 (6): 934 940.

Nasiri, A. H., A. Towhidi and S. Zeinoaldini, 2012. Combined effect of DHA and $\alpha$ - tocopherol supplementation during bull semen cryopreservation on sperm characteristics and fatty acid composition. Andrology, 44 (1): 550 555.

Peña, F. J., H. Rodriguez Martinez, J. A. Tapia, C. Ortega Ferrusola, L. Gonzalez Fernandez and B. Macias Garcia, 2009. Mitochondria in mammalian sperm physiology and pathology: a review. Reproduction Domestic Animal, 44: 345 349.

Rosato, M. P. and N. Iaffaldano, 2013. Cryopreservation of rabbit semen: comparing the effects of different cryoprotectants, cryoprotectant - free vitrification, and the use of albumin plus osmoprotectants on sperm survival and fertility after standard vapor freezing and vitrification. Theriogenology, 79 (3): 508 - 516.
Salmani, H., M. M. Nabi, H. Vaseghi - Dodaran, M. B. Rahman, A. M. Sangcheshmeh, M. Shakeri, A. Towhidi, A. Z. Shahneh and M. Zhandi, 2013. Effect of glutathione in soybean lecithin-based semen extender on goat semen quality after freeze - thawing. Small Ruminant Research, 112 (1): $123-127$.

Saraswat, S., S. D. Kharche and S. K. Jindal, 2014. Impact of reactive oxygen species on spermatozoa: A balancing act between beneficial and detrimental effects. Iranian Journal of Applied Animal Science, 4 (2): 247 - 255.

Shahani, S. K., S. G. Revell, C. Argo and R. D. Murray, 2012. Effects of Some Respiratory and Glycolytic Inhibitors on Mitochondrial Functionality in Bovine Semen. The Open Andrology Journal, 4: 12 - 20.

SPSS, 2013. Statistical package for social sciences, IBM $^{\circledR}$ SPSS Statistics Data Editor 22.0 License Authorization Wizard, Chicago, USA.

Sukho, P., H. Juwarahawong, S. Sangiam and K. Kaeoket, 2013. The effect of adding L - Cysteine in modified Kenny's extender on the quality of chilled stallion semen at $5^{\circ} \mathrm{C}$. Journal of Applied Animal Science, 6 (1): 43 - 52.

Szafner, G., D. Bicanic, K. K. Gaal and Doka, 2012. Direct measurement of thermal effusively of avian eggs and their constituents: A photopyroelectric study. Food Technology Biotechnology, 50 (3): 350 - 354.

Van Reenen, G. M. and J. F. T. Griffin, 1994. Separating dead from live sperm in thawed frozen merino semen does not enhance conception rate. Proceedings of the New Zealand Society of Animal Production, 54: 43 - 44.

Waheed, S., N. Ahmad, Najib - ur - Rahman, H. Jamil - ur - Rahman, M. Younis and S. Iqbal, 2012. Evaluation of duck egg yolk for the cryopreservation of (Nili-Ravi) buffalo bull semen. Animal Reproduction Science, 13: 95 99.

Wu, M., G. Qing - lian Gao, Yu - Shi and C. Kuan Wei, 2012. A research on determination of lecithin in eggs by applying microwave digestion techniques and spectrophotometry. Iranian Journal of Chemistry and Chemical Engineering, 31 (2): $15-20$.

Yotov, S., 2015. Effect of TFC-based extenders with soybean lecithin and / or low concentration of glycerol on the quality of goat chilled - stored semen. Intentional Journal Current. Microbiology Applied Science, 4 (3): 752 - 761. 
الإستجابة الفسيولوجية للحيوانات المنوية لذكور الماعز لليسيثين فول الصويا كبديل لأصناف صفار البيض فى مخففات

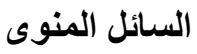

عز الدين إبر اهيم خليفة قسم بحوث الأغنام والداعز، معطل بحوث الإنتاج الحيوانى، وزارة النزاعة، الدقى، مصر

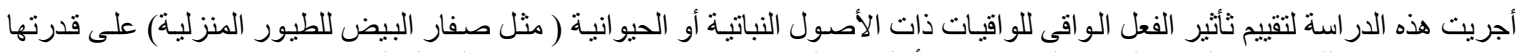

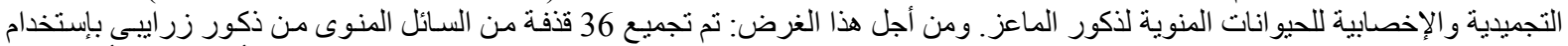

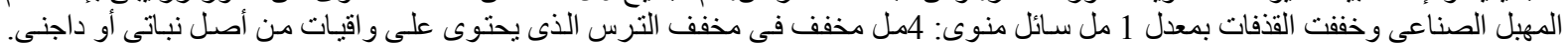

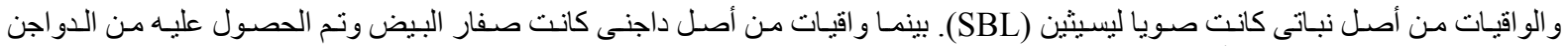

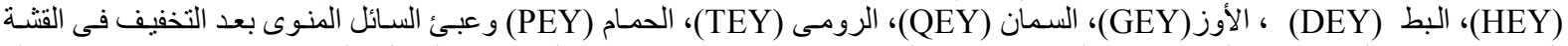

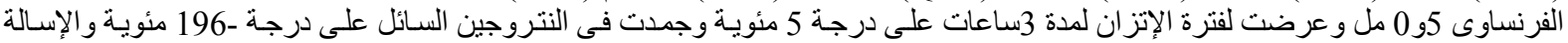

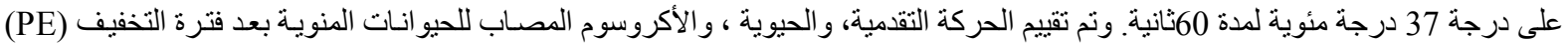

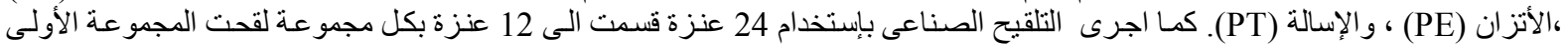

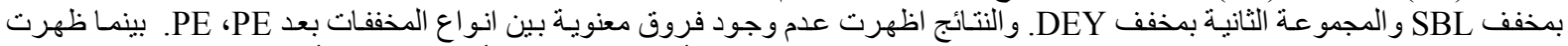

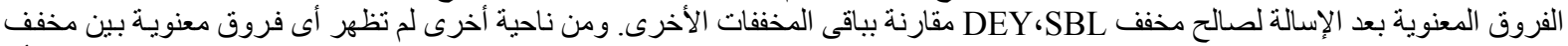

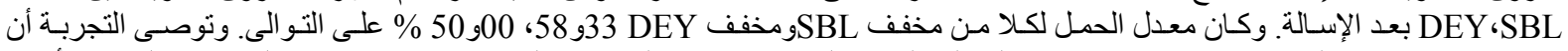

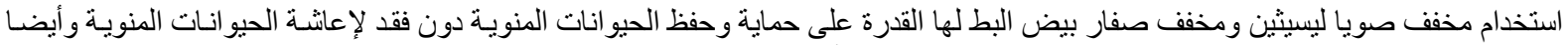

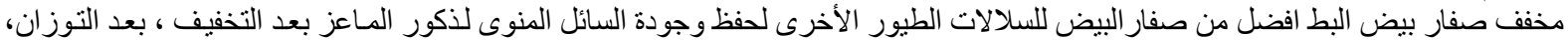

